\title{
MODEL PERILAKU NASABAH PADA BANK PEMBIAYAAN RAKYAT SYARI'AH (BPRS) DI MEDAN
}

\author{
Ihsan Effendi 1)*, Miftahuddin ${ }^{2)}$, Mitra Musika ${ }^{3)}$, Indawati Lestari 4) \\ ${ }^{1)}$ Program Studi Manajemen, Universitas Medan Area, Indonesia \\ 2) Program Studi Manajemen, Universitas Medan Area, Indonesia \\ 3) Program Studi Manajemen, Universitas Medan Area, Indonesia \\ 4) Politeknik Unggul LP3M, Medan \\ ihsaneffendi@yahoo.com ${ }^{1)}$, miftahuddinmurad48@gmail.com ${ }^{2)}$, mitra@ staff.uma.ac.id $^{3)}$, \\ $\underline{\text { Indahtaca@gmail.com }}{ }^{4}$ )
}

\begin{abstract}
Penelitian ini dilakukan untuk merumuskan model yang tepat untuk nasabah tabungan di Bank Pembiayaan Rakyat Syariah (BPRS) di Sumatera Utara sehingga dapat menjadi model bagi Bank Pembiayaan Rakyat Syariah (BPRS) di Indonesia. Hasil penelitian ini menunjukkan variabel sistem syariah, promosi memberikan daya tarik dalam pembentukan niat untuk membuka rekening tabungan di BPRS. Namun layanan tidak mempengaruhi pembentukan niat untuk menjadi pelanggan. Studi ini juga menegaskan bahwa Theory of Reasoned Action (TRA) dapat digunakan dalam riset konsumen tentang BPRS.
\end{abstract}

Keywords: Sistem syariah, perilaku syariah, Bank Pembiayaan Rakyat Syariah (BPRS) 


\section{PENDAHULUAN}

Awal perkembangan perbankan syari'ah di Indonesia sudah cukup pesat. Namun walaupun tujuan dari BPRS sangat mulia, jumlah BPRS selama 2013-2015 relatif stagnan dan hanya mengalami sedikit perubahan dibandingkan dengan Bank Perkreditan Rakyat (BPR). Pertumbuhannya hanya dari 158 menjadi 160 BPRS. Sedangkan jumlah kantor masih tetap 398. Padahal bila dilihat dari latar belakang berdirinya, Bank Pembiayaan Rakyat Syari'ah (BPRS) merupakan jawaban terhadap tuntutan dan kebutuhan kalangan umat Muslim. dari unsur riba yang dinyatakan haram. Fakta yang ada di lapangan menunjukkan banyak BPRS yang tenggelam dan bubar (Noversyah dan Hotniar Siringoringo, 2015)

BPRS berdiri berdasarkan UndangUndang No. 7 Tahun 1992 tentang Perbankan dan Peraturan Pemerintah (PP) No. 72 Tahun 1992 tentang Bank yang berdasarkan prinsip bagi hasil. Pada pasal 1 (butir 4) UndangUndang No. 10 Tahun 1998 disebutkan bahwa Bank Syari'ah adalah bank yang melaksanakan kegiatan usaha berdasarkan prinsip Syari'ah. Keberadaan BPRS diperkuat lagi dengan Undang-undang No. 21 tahun 2008 tentang Perbankan Syari'ah. Walaupun perbankan syari'ah sudah didukung oleh peraturan perundang-undangan, namun belum mampu juga bersaing dengan konvensional lainnya (Bank Indonesia, 2018)

Terdapat beberapa tujuan yang dikehendaki dari berdirinya BPRS. Kehadiran BPRS menjadi sumber permodalan bagi pengembangan usaha-usaha masyarakat golongan ekonomi lemah, sehingga pada gilirannya dapat meningkatkan pendapatan dan kesejahtertaan mereka. Selain itu kehadiran BPRS adalah untuk membina ukhuwah Islamiyah melalui kegiatan ekonomi dalam rangka peningkatan pendapatan menuju kualitas hidup yang memadai. Hal ini mengandung makna bahwa dalam BPRS ditumbuhkan nilai ta'awun (saling membantu) antara pemilik modal dengan pemilik pekerjaan. Dengan nilai ta'awun inilah akan tumbuh kebersamaan antara bank dan nasabah yang merupakan faktor terpenting dalam mewujudkan Ukhuwah Islamiyah (Salamah, Wahyuni, \& Arifin, 2013).

Salah satu tujuan BPRS adalah meningkatkan kesejahteraan ekonomi umat Islam terutama kelompok masyarakat ekonomi lemah yang pada umumnya khususnya kelompok Usaha Kecil Menengah (UKM). Masyarakat menjadi nasabah bank Islam tidak hanya semata-mata menghitung untung rugi, tidak lagi terpengaruh dengan hal-hal yang bersifat duniawi. Panggilan jiwalah yang mendorongnya, karena didalamnya mengandung nilai-nilai spiritual/spiritual marketing (Kertajaya dan Sula, 2006). Dalam bahasa syari'ah, keseluruhan proses yang dilakukan oleh perbankan dalam persepsi nasabah tidak ada yang bertentangan dengan prinsip-prinsip muamalah, kegiatan bank Islam harusnya mengandung nilai-nilai ibadah.

Pada awal pendirian bank syari'ah menurut Wibisana, Yusuf, Iwan Triyuwono, Nurkholis, dan Yustika (1999) pemahaman tentang bunga bank, menunjukkan bahwa sebagian besar masyarakat mengatakan haram sehingga menjadi alternatif bagi umat Islam untuk menyimpan dananya di Bank. Untuk meraih pasar umat Islam menurut Anita Rahmawaty (2014) dibutuhkan promosi untuk mempengaruhi minat masuk ke bank syari'ah.

BPRS sebagai lembaga keuangan Islam masih banyak mengalami kendala. Banyak nasabah masih ragu tentang pelaksanaan system syariah yang dilakukan oleh BPRS. Mereka belum yakin BPRS dalam transaksinya bersih dari riba, bunga, ghoror, dan maisir dan praktik Bank syariah bagi sebagian kalangan belum sepenuhnya syariah. Walaupun Fatwa Majelis Ulama Indonesia nomor 1 Tahun 2004 tidak dibolehkan melakukan transaksi yang didasarkan bunga, namun, fatwa tersebut belum cukup kuat mendorong masyarakat bermigrasi menuju Bank Syariah. Selain itu belum terdapat 
standar dalam produk-produk syariah yang berpotensi untuk menyimpang secara syariah.

Pelayanan di BPRS sering menjadi kendala khususnya pelayanan di banking hall. Pelayanan sering membuat nasabah beralih ke bank lain karena tidak puas. Keluhan pelayanan juga terasa di luar bank. Pihak BPRS sering tidak memahami masalah yang dihadapi konsumen sehingga sering terjadi kesalahpahaman anatra pihak pemasar dengan pihak nasabah. Tentunya hingga saat ini BPRS terus menerus berupaya memperbaikan layanan BPRS. Padahal kualitas pelayanan bank sangat penting sepeti yang diungkap oleh Polat, Yeşilyaprak dan Kaya (2014) bahwa nasabah bank akan memilih bank Syari'ah yang memiliki pada jasa bank yang berkualitas pelayanan yang tinggi dan pelayanan yang cepat dalam hal kebutuhan dari pelanggan.

Selain itu, promosi sering menjadi kendala BPRS. BPRS sebagai lembaga keuangan kecil masih belum memiliki sistem pemasaran yang luas. Hanya segelintir BPRS memiliki jaringan yang luas. Pemasaran bank syariah tidak saja masalah pemasaran tapi juga menyangkut masalah sosial dan budaya. Untuk itu pemasaran BPRS lebih banyak dalam bentuk sosialisasi dan pertemuan tatap muka dibandingkan dengan menggunakan teknologi. Tentunnya hal ini akan memperlambat perkembangan dari BPRS itu sendiri.

Memahami kosumen Lemabaga Syari'ah tidak cukup dengan mengkaji prinsipprinsip Islam. Menurut Slater (1997) perusahaan harus memahami konsumen perilaku konsumen secara untuk bisa bertahan dalam persaingan perbankan. Kotler (2011) berpendapat konsumen sudah sangat mengerti antara kualitas atau manfaat dari suatu produk perbankan dan dapat memandang pada produk relatif untuk pengorbanan mereka bayar. Salah satu faktor penting yang mempengaruhi perilaku konsumen untuk membeli atau memanfaatkan suatu produk adalah niat. Niat merupakan pengorganisasian proses kognisi, emosi dan kecenderungan untuk bertindak. Salah satu teori yang bisa menjelaskan hubungan sikap, minat dan perilaku adalah Theory of Reasoned Action (TRA) (Ajzen and Fishbein, 1975). Menurut Effendi (2015) Theory of Reasoned Action (TRA) dapat digunakan untuk melihat berbagai prilaku konsumen dalam memenuhi kebutuhannya.

\section{TINJAUAN PUSTAKA}

Beberapa peneliti, seperti Echchabi dan Olaniyi (2012) mempelajari penerapan perbankan Syari'ah, menemukan sikap, niat memiliki pengaruh signifikan terhadap perilaku untuk menjadi nasabah bank Syari'ah. Selanjutnya, Salamah, Wahyuni dan Arfin (2013) menegaskan adanya keabsahan konstruk TRA dalam mengkaji perilaku nasabah perbankan Syari'ah di Surakarta, Indonesia. Hasil ini konsisten dengan studi Amin (2012) di mana pengetahuan tentang perbankan Syari'ah, sikap dan norma subjektif ditemukan memiliki hubungan positif dengan niat untuk mengadopsi perbankan Islam antara pelanggan.

Niat menjadi komponen pada perbankan Syari'ah dan perbankan Syari'ah dapat dikaji menggunakan model TRA, model ini memprediksi niat pelanggan jauh lebih baik dari pada model Theory Of Planned Behavior (TPB) (Gumela, Othman, Rosylin dan Mohd Yusof, 2015). Dari hasil penelitian Mark Loo (2010) menunjukkan Muslim sebagai pendukung utama Perbankan Syari'ah dan dari dimensi kognitif atau pengetahuan adalah "faktor penatik dari perbankan Islam. Penelitian di Pakistan menunjukkan prinsipprinsip bagi hasil Islam yang bebas riba merupakan daya tarik bagi konsumen untuk memilih perbankan Syari'ah dan motif agama telah mempengaruhi pelanggan untuk memilih bank Syari'ah. Selanjutnya pengetahuan nasabah perlu ditingkatkan agar industri perbankan Syari'ah tumbuh dengan pesat dengan promosi perbankan Syari'ah akan bisa meningkatkan produk keuangan Islam. Promosi yang tepat akan membantu untuk meningkatkan goodwill dan reputasi bank 
p-ISSN : 2301-7775

e-ISSN : 2579-8014

NIAGAWAN Vol 9 No 3 November 2020

Syari'ah (Abdul Ghafoor Awan dan Maliha

Azhar, 2014). 




Gambar 1 Gambaran Penelitian

\section{METODE PENELITIAN}

Data-data yang dibutuhkan dalam penelitian ini bersumber dari dua data primar. Data primer bersumber dari daftar pertanyaan (Questioner) yang diarahkan kepada nasabah BPRS pinjaman di Medan.

Populasi penelitian ini adalah nasabah deposan BPRS yang secara individu memiliki pinjaman . Data populasi dikumpulkan dengan metode random sampling. Populasi diperoleh dari masing-masing Bank Pembiayaan Rakyat Syari'ah (BPRS). Untuk penentuan jumlah sampel menggunakan 276 responden Nasabah penyimpan pada BPRS.

Untuk mengukur Validitas dan Reliabilitas adalah dengan evaluasi atau uji kecocokan model pengukuran. Evaluasi ini dilakukan terhadap setiap konstruk atau model pengukuran (hubungan antara sebuah variable laten dengan beberapa variabe yang teramati secara terpisah. Untuk mengukur reliabilitas dalam SEM digunakan composite reliability measure dan variable extracted measure.yaitu : Standard loading dapat diperoleh secara langsung dari keluaran lisrel 8.8 student. Ekstrak varian mencerminkan jumlah varian keseluruhan indikator-indikator yang dijelaskan oleh variabel laten. Reliabilitas dilihat dari nilai Construct Reliability $(\mathrm{CR}) \geq 0.70$ dan Variance Extracted (VE) lebih besar dari 0.5.

Evaluasi terhadap validitas dari model pengukuran dikatakan mempunyai validitas yang baik terhadap konstruk atau variabel latennya, jika Nilai -t muatan faktornya (Faktor Loading) lebih besar dari nilai kritis (1,96 atau praktisnya $\geq 20$ ) dan evaluasi terhadap validitas (validity) dari model pengukuran dapat menunjukkan muatan faktor standar (Standard Loading Factor, SLF). Konstruk atau model pengukuran mempunyai validitas yang baik jika Standar Loading Faktor SLF > 0.5.

Model analisis menggunakan model persamaan struktural atau Structural Equation Modelling (SEM) adalah kumpulan dari teknikteknik statistikal yang memungkinkan pengujian 
sebuah rangkaian hubungan yang relatif rumit secara simultan (Ferdinand, 2000).

Evaluasi terhadap kesesuaian model melalui telaah terhadap berbagai kriteria goodness of fit dilakukan dengan : p-value, RMSEA, NFI, NNFI, CFI, IFI, RFI, Std. RMR, dan GFI. Pengujian model menggunakan overall model dan statistic goodness of fit beserta pengujian koefisien jalur : Uji signifikansi koefisien jalur $(\alpha$ dan $\beta)$ menggunakan uji t dengan signifikansi $\mathrm{p}<0,05$
NIAGAWAN Vol 9 No 3 November 2020 serta memenuhi kriteria Statistic Goodness of Fit dengan semua koefisien dalam model signifikan

\section{HASIL PENELITIAN DAN PEMBAHASAN Reliabilitas}

Reliabilitas adalah evaluasi atau uji kecocokan model pengukuran. Evaluasi ini dilakukan terhadap setiap konstruk untuk melihat hubungan antara sebuah variable laten dengan variabel yang teramati dengan cara terpisah.

Tabel 1 Standar Loading Faktor (SLF) Variabel Sistem Syariah (X1)

\begin{tabular}{llll}
\hline Variabel & \multicolumn{2}{l}{ X1 } & \multirow{2}{*}{ Kesimpulan } \\
\cline { 2 - 3 } & SLF & Nilai t & Baik \\
\hline X11 & 0.55 & 6,04 & Baik \\
X12 & 0,79 & 6,90 & Baik \\
\hline
\end{tabular}

Sumber : Data yang Diolah 2020

Hasil pengukuran dan evaluasi reliabiitas dari variabel Sistem Syariah terdapat dua variabel yang memiliki kesimpulan baik yaitu variabel X11 dan X12 sedangkan variabel X13 memiliki reliabilitas tidak baik. Maka variabel X13 tidak dimasukkan dalam model.

Tabel 2. Standar Loading Faktor (SLF) Variabel Promosi (X2)

\begin{tabular}{llll}
\hline Variabel & $\mathrm{X} 2$ & & \multirow{2}{*}{ Kesimpulan } \\
\cline { 2 - 3 } Laten & SLF & Nilai t & Baik \\
\hline X21 & 0.87 & 16.81 & Baik \\
X22 & 0.82 & 15.51 & Tidak Baik \\
X23 & 0.27 & 1,60 & \\
\hline
\end{tabular}

Sumber : Data yang Diolah 2020

Hasil pengukuran dan evaluasi reliabiitas dari variabel laten Promosi (X2) terdapat dua variabel yang memiliki kesimpulan baik yaitu variabel X21, dan X22 sedangkan variabel X23 memiliki reliabilitas tidak baik. Dengan demikian variabel X23 tidak dimasukkan dalam model.

Tabel 3. Standar Loading Faktor (SLF) Variabel Pelayanan (X3)

\begin{tabular}{llll}
\hline Variabel & $\mathrm{X} 3$ & & Kesimpulan \\
\cline { 2 - 3 } Laten & SLF & Nilai $\mathrm{t}$ & Baik \\
\hline X31 & 0.82 & 5.80 & Baik \\
X32 & 0.82 & 5.50 & \\
\hline
\end{tabular}


Sumber : Data yang Diolah 2020

Hasil pengukuran dan evaluasi reliabiitas dari variabel laten Pelayanan (X3) terdapat kedua variabel yang memiliki kesimpulan baik dengan demikian variabel X31 dan X32 dimasukkan dalam model.

Tabel 4. Standar Loading Faktor (SLF) Vaiabel Niat (Y1)

\begin{tabular}{llll}
\hline Variabel & Y1 & \multirow{2}{*}{ Kesimpulan } \\
\cline { 2 - 3 } Laten & SLF & Nilai t & Baik \\
\hline Y11 & 0.50 & 8.18 & Baik \\
Y12 & 0.78 & 13.63 & Baik \\
Y13 & 0.52 & 8.54 & \\
\hline
\end{tabular}

Sumber : Data yang Diolah 2020

Hasil pengukuran dan evaluasi reliabiitas dari variabel laten Niat (Y1) terdapat tiga variabel yang memiliki kesimpulan baik

yaitu variabel Y11, Y122 dan Y133. Sehingga semua indikator masuk dalam perhitungan.

Tabel 5. Standar Loading Faktor (SLF) Prilaku Syariah ( $\left.\mathrm{Y}_{2}\right)$

\begin{tabular}{llll}
\hline Variabel & Y2 & & \multirow{2}{*}{ Kesimpulan } \\
\cline { 2 - 3 } Laten & SLF & Nilai t & Baik \\
Y21 & 0.26 & 3.56 & Baik \\
Y22 & 0.90 & 5.88 & Baik \\
Y23 & 0.60 & 5.36 & \\
\hline
\end{tabular}

Sumber : Data yang Diolah 2020

Hasil pengukuran dan evaluasi reliabiitas dari variabel laten variabel Perlaku konsumen memiliki kesimpulan baik ydengan demikian sub variabel Y21, Y22 dan Y23. dapat dimasukkan dalam model.

\section{Validitas}

Evaluasi terhadap validitas (validity) dari model pengukuran dapat dilihat pada tabel 4.17 dimana dapat menunjukkan muatan faktor standar (Standard Loading Factor, SLF). Dari tabel tersebut dapat dikatakan konstruk atau model pengukuran mempunyai validitas yang baik karena Standar Loading Faktor SLF > 0.5 (Santoso, 2002).

Standard loading dapat diperoleh secara langsung dari keluaran listrel 8.8 student dan $\mathrm{e}_{\mathrm{j}}$ adalah measurement error untuk setiap error dari setiap indikator atau variabel yang teramati. Ekstrak varian mencerminkan jumlah varian keseluruhan indikator-indikator yang dijelaskan oleh variabel laten.

Tabel 6. Construct Reliability, Variance Extracted, Reliability Model Stability Alienation

$\begin{array}{llll}\text { Variabel } & \text { CR } & \text { VE } & \text { Kesimpulan Reabilitas }\end{array}$




\begin{tabular}{lllc}
\hline Niat Y1 & & \\
Perilaku Konsumen Y2 & 0.91 & 0.78 & Baik \\
System Syariah X1 & 0.90 & 0.58 & Baik \\
X2 & 0.77 & 0.64 & Baik \\
X3 & 0.72 & 0.57 & Baik \\
\hline
\end{tabular}

Sumber : Analisis Data Primer (Lisrel 8.5)

Hasil perhitungan validitas di atas, dapat dikatakan semua variabel yang digunakan valid dimana dapat dilihat dari semua nilai Construct Reliability $(\mathrm{CR}) \geq 0.70$ dan Variance Extracted (VE) $\geq 0.5$ Dengan demikian bisa disimpulkan bahwa ke semua variabel memberikan hasil yang baik.

\section{Analisis Data}

$\begin{array}{crrr} & \text { Untuk Structural } & \text { Equation } & \text { Modelling } \\ \text { (SEM) } & \text { digunakan } & \text { sebagai } & \text { untuk }\end{array}$ mengkonfirmasi suatu model, model tersebut harus dittetapkan dengan benar berdasarkan pada jenis analisis yang diteliti.. Untuk membangun model yang tepat digunakan dua macam variabel, yaitu variabel eksogen dan endogen. Variabel eksogen sebagai variabel pengirim panah, yang menunjukkan sebagai variabel memprediksi variabel endogen. Variabel endogen sebagai penerima dari panah dalam model. Adapun hasil standard solution untuk Model ini adalah sebagai berikut :

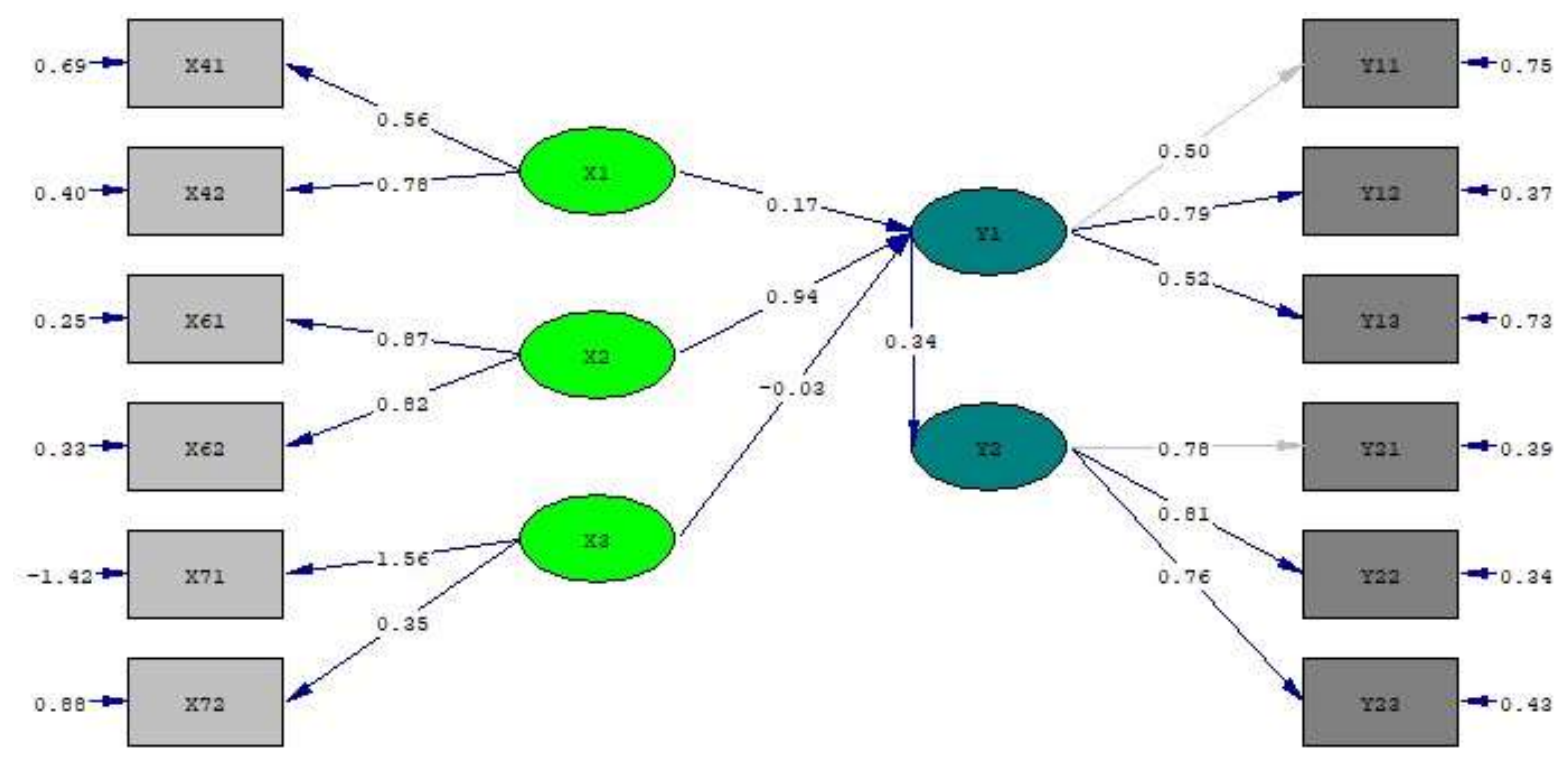

Chi-Square=61.89, $d f=47, P-v a l u e=0.07138$, RMSEA $=0.034$

Gambar 2. . Hasil Analisis Data Standard Solution 


\begin{tabular}{clc}
\hline No. & \multicolumn{1}{c}{ Pengaruh Antar Variabel Laten } & $\begin{array}{c}\text { Nilai Standard } \\
\text { Solution Model A }\end{array}$ \\
\hline 1 & Pengaruh Sistem Syariah (X1) terhadap Niat (Y1) & 0.17 \\
2 & Pengaruh Promosi (X2) terhadap Niat (Y1) & 0.94 \\
3 & Pengaruh Pelayanan (X3) terhadap Niat (Y1) & -0.03 \\
4 & Pengaruh Niat (Y1) terhadap Prilaku pembelian (Y2) & 0.34 \\
\hline
\end{tabular}

Sumber : Data Olahan (2020)

Setelah model pengukuran standard solution, langkah berikutnya adalah melakukan analisis model struktural dari model penelitian, analisis ini berkaitan dengan uji hipotesis- hipotesis penelitian. Hipotesis penelitian diterima jika angka absolut nilai $\mathrm{t}>1.96$ dengan tanda koefisien sesuai dengan hipotesis penelitian yang diajukan (positif atau negatif).

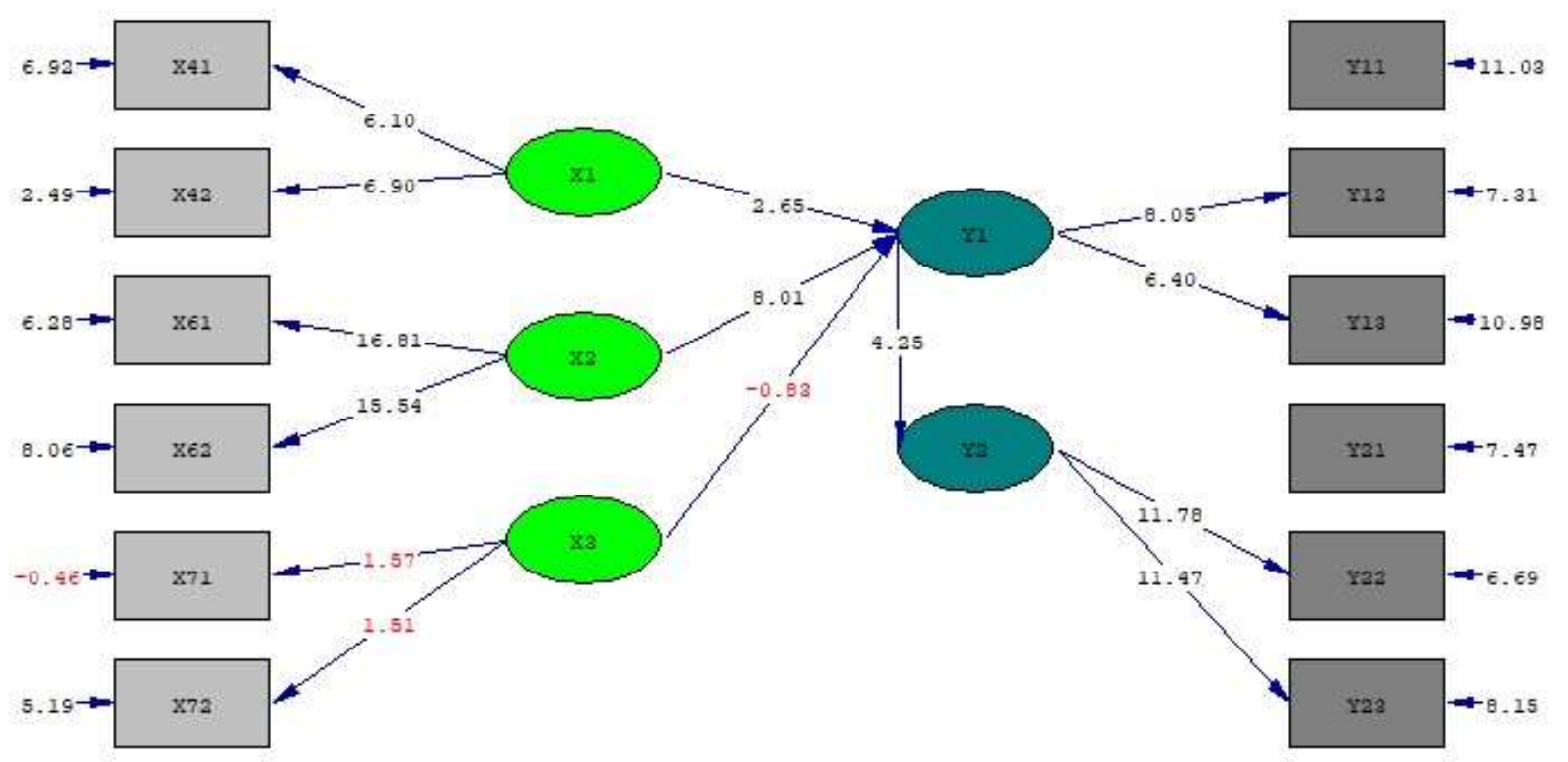

Chi-Square $=61.89, d f=47, \mathrm{P}-\mathrm{value}=0.07138, \mathrm{RMSEA}=0.034$

Gambar 3 . Hasil Perhitungan Lisrel T-Value

Tabel 8. Hasil Uji Signifikansi Model Struktural Penelitian

\begin{tabular}{llcl}
\hline Hipotesis. & \multicolumn{1}{c}{ Pengaruh Antar Variabel Laten } & $\begin{array}{c}\text { Nilai } \\
\text { t hitung }\end{array}$ & $\begin{array}{c}\text { Kesimpulan } \\
\text { Hasil Uji } \\
\text { Signifikansi }\end{array}$ \\
\hline Hipotesis 1 & Pengaruh Sistem Syariah (X1) terhadap Niat (Y1) & 2,65 & $\mathrm{H}_{0}$ ditolak \\
Hipotesis 2 & Pengaruh Promosi (X2) terhadap Niat (Y1) & 8,01 & $\mathrm{H}_{0}$ ditolak \\
Hipotesis 3 & Pengaruh Pelayanan (X3) terhadap Niat (Y1) & $-0,82$ & $\mathrm{H}_{0}$ diterima \\
Hipotesis 4 & Pengaruh Niat (Y1) terhadap Prilaku Syariah (Y2) & 4,25 & $\mathrm{H}_{0}$ ditolak \\
\hline
\end{tabular}


Untuk melihat kecocokan model dilakukan pengujian-pengujian keselarasan dengan membandingkan model yang diberikan dan model alternatif (Goodness-of-fit tests comparing the given model with an alternative model), dimana pengukuran-pengukuran

Tabel 9. Goodness Of Fit Index (GOFI) Model Struktural

\begin{tabular}{lcll}
\hline \multicolumn{1}{c}{ GOFI } & Nilai Hasil Hitung & $\begin{array}{l}\text { Nilai Standar Untuk } \\
\text { Kecocokan Baik }\end{array}$ & Kesimpulan \\
\hline p-value & 0.07138 & p-value $\geq 0.05$ & Baik \\
RMSEA & 0.034 & RMSEA $\leq 0.08$ & Baik \\
NFI & 0.94 & NFI $\geq 0.90$ & Baik \\
NNFI & 0.98 & NNFI $\geq 0.90$ & Baik \\
CFI & 0.98 & CFI $\geq 0.90$ & Baik \\
IFI & 0.98 & IFI $\geq 0.90$ & Baik \\
RFI & 0.92 & RFI $\geq 0.90$ & Baik \\
Std. RMR & 0.049 & Std. RMR $\leq 0.05$ & Baik \\
GFI & 0.94 & GFI $\geq 0.90$ & Baik \\
\hline Sur
\end{tabular}

Sumber : Data Primer Diolah (2020)

Dari tabel Goodness Of Fit Index (GOFI) Model Struktural menujukkan bahwa model penelitian sudah baik karena semua indikator yaitu p-value, RMSEA, NNFI, CFI, IFI, RFI, Std. RMR, dan GFI baik atau good fit. Dengan demikian model penelitian ini dianggap sudah baik dan sesuai dengan data yang ada..

Paparan ini menunjukkan bahwa variabel-variabel perilaku konsumen muncul dari proses yang bertahap, yang diawali dengan pengembangan asumsi terhadap proses dan hasil pengukuran, pengembangan model pengukuran yang kemudian menghasilkan variabel perilaku nasabah BPRS dapat dikatakan sudah sesuai dengan teori yang dipakai.

\section{Pembahasan}

Ttingkat sistem syariah dalam penelitian ini berpengaruh positif signifikan terhadap sniat untuk menyimpan dana pada BPRS. Apabila mengacu pada data dalam keselarasan ini membandingkan model yang dibuat oleh peneliti untuk dicocokkan dengan model yang lain. Untuk itu dapat dilihat Goodness Of Fit Index (GOFI) Model Struktural sebagai berikut: 
yang baik maka nasabah cepat mengerti dan memahami produk yang disediakan oleh bank syariah dibandingkan produk bank lain. Perbankan syariah merupakan indutri jasa yang relatif baru dimana menerapkan syariah Islam disetiap aktivitas perbankannya maka perlu adanya pemahaman dan sosialisasi kepada masyarakat tentang produk melalui promosi. Pada penelitian ini promosi berpengaruh signifikan terhadap sikap nasabah BPRS. Pihak BPRS telah banyak melakukan berbagai kegiatan promosi di lingkungan BPRS masingmasing. Walaupun BPRS bukan bank besar namun pesan yang disampaikan cukup berarti bagi nasabah.

Selain promosi masyarakat mempertimbangkan untuk memilih bank dengan alasan pelayanan bank. Bank yang memiliki pelayanan yang baik dan strategis sangat memudahkan nasabah dalam berurusan dengan bank. Pelayanan merupakan perilaku produsen dalam rangka memenuhi kebutuhan dan keinginan konsumen demi tercapainya kepuasan pada konsumen. Semakin baik kualitas pelayanan yang diberikan oleh bank maka nasabah semakin puas terhadap layanan tersebut. BPRS merupakan bank kecil namun BPRS belum mampu memberikan pelayanan yang maksimal dalam membentuk perilaku syariah..

\section{KESIMPULAN DAN SARAN Kesimpulan}

Ada pengaruh signifikan sistem Syari'ah terhadap niat nasabah untuk menggunakan jasa BPRS di Provinsi Sumaera Utara. Ada pengaruh promosi terhadap niat nasabah untuk menggunakan jasa BPRS di Provinsi Sumaera Utara. Tidak ada pengaruh pelayanan terhadap niat nasabah untuk menggunakan jasa BPRS di Provinsi Sumaera Utara. Ada pengaruh niat terhadap perilaku syariah untuk menggunakan jasa BPRS di Provinsi Sumaera Utara

\section{Saran}

Perlu sosialisai lebih dalam tentang ilmu bank syariah oleh pihak perbankan. Selama ini pengetahuan bank syariah lebih banyak diperoleh dari pengajian-pengajian ketimbang dari bank syariah. Promosi lebih diintensifkan lebih tajan karena masih banyak potensi nasabah yang belum terjangkau. Promosi seharusnya dilakukan lebih agresif untuk memperkenalkan BPRS. Secara teori penelitian ini memisahkan beberapa variabel untuk memperkuat terori-teori tentang prilaku konsumen.

\section{REFERENSI}

Abdul Ghafoor Awan \& Maliha Azhar (2014), Consumer Behaviour Towards Islamic Banking In Pakistan, European Journal of Accounting Auditing and Finance Research Vol.2, No.9,pp.42-65, Published by European Centre for Research Training and Development UK (www.eajournals.org)

Ajzen, I, Fishbein, M (1975), Belief, Attitude, Attention and Behavior, An Introduction to Theory and Research, Addison Wesley Publising Company.

Amin, H. (2012). Patronage factors of Malaysian local customers toward Islamic credit cards. Management Research Review, Vol. 35 No. 6, 512-530.

Anita Rahmawati (2014), Pengaruh Persepsi Tentang Bank Syari'ah Terhadap Minat Menggunakan Produk Di BNI Syari'ah Semarang, ADDIN, Vol. 8, No. 1

Don Slater (1997), Consumer Culture and Modernity, Cambridge, UK: Polity Press

Echchabi A dan Olaniyi O. N., (2012) Malaysian consumers' preferences for 
Islamic banking attributes, International Journal of Social Economics, Vol. 39 No. 11: $859-874$

Effendi I, Paham Ginting, Arlina Nurbaity Lubis, \& Khaira Amalia Fachruddin (2015), Analysis of Consumer Behavior of Organic Food in North Sumatra Province, Indonesia, Journal of Business and Management, Vol. 4 No.1, 44-58

Ferdinand A.T., 2000, SEM-Structural Equation Model Amos 4.0, Penerbit Semarang, Semarang

Gumela A. M., Othman M. A., Rosylin dan Yusof Mohd (2015), Critical Insights Into An Integrated Literature Review On Customers' Adoption of Islamic Banking Research, International Journal of Scientific Research and Innovative Technology, Vol. 2 No. 6; 45-57

Kertajaya, $\mathrm{H}$ dan Muhammad Syakir Sula (2006), Syari'ah Marketing. Bandung : Mizan.

Kotler P. (2011), Marketing Management Millenium Edition, Tenth Edition, Prentice-Hall, Inc. Upper Saddle River, New Jersey

Mark Loo (2010), Attitudes and Perceptions towards Islamic Banking among Muslims and Non-Muslims in Malaysia: Implications for Marketing to BabyBoomers and X-Generation, International Journal of Arts and Sciences Vol. 3 No. 13: 453-485

Noversyah dan Hotniar Siringoringo (2015), The Theory of Reasoned Action of Islamic Banking Consumer Behavior, International Journal of Research in
NIAGAWAN Vol 9 No 3 November 2020 Management Science and Technology Vol. 3 Issue. 5, ; 3501-3511

Polat A., Yeşilyaprak M. dan Kaya R. (2014) Understanding Islamic Bank Selection of Customers: A Field Research from Turkish Participation Banks, International Journal of Financial Research, Vol. 5, No. $4 ; 22-38$

Salamah Wahyuni, S., \& Arifin, T. (2013). Knowledge as an antecedent variable of intention to use Islamic banking product Retrieved Tuesday, 15th July, 2015,from http://aasic2013.permitha.net/Proceedings /ICBESS_Proceeding/ Volume/ icbessp028.pdf

Santoso S., 2002, Struktural Equatiion Modelling Konsep dan Aplikasi dengan $A M O S$, PT. Elex Media Komputindio Kelompok, Gramedia, Jakarta

Wibisana, Yusuf, Iwan Triyuwono, Nurkholis, dan Yustika (1999) "Studi Pendahuluan Persepsi Masyarakat tentang Bank Perkreditan Rakyat Syari'ah", Malang: Centre for Business \& Islamic Economics Studies - Faculty of Economics Brawijaya University dan Bank Indonesia Jakarta, 1999.

UU No. 7 Tahun 1992

Undang-Undang No. 10 Tahun 1998

Undang-undang No. 21 tahun 2008

(PP) No. 72 Tahun 1992

Laporan Tahunan (Bank Indonesia, 2018)

Fatwa Majelis Ulama Indonesia nomor 1 Tahun 2004 
p-ISSN : 2301-7775

e-ISSN : 2579-8014

NIAGAWAN Vol 9 No 3 November 2020 